\title{
El papel de la Unión Europea en la cooperación para el desarrollo: opciones y límites al vínculo entre gobernanza y desarrollo
}

\author{
José Ángel Sotillo Lorenzo \\ Profesor Titular de Relaciones Internacionales \\ Universidad Complutense de Madrid
}

\begin{abstract}
Sumario: I. Introducción. - II. Breve diagnóstico sobre el estado de la cooperación para el desarrollo. - III. Política exterior y cooperación en la Unión Europea. - IV. El papel de la Unión Europea en la cooperación para el desarrollo. 1. La doctrina europea sobre la cooperación para el desarrollo. 2. Política y gestión de la cooperación europea. 3. La cooperación europea en el mundo. $-\mathrm{V}$. La cooperación europea y la gobernanza global: riesgos y desafíos. - VI. Conclusiones: un futuro incierto.
\end{abstract}

Resumen: La cooperación para el desarrollo constituye uno de los activos más importantes de la presencia de la Unión Europea en el mundo. Se ha ido consolidando progresivamente, para ser hoy uno de los actores más importantes de la ayuda oficial al desarrollo, tanto por sus aportaciones - que la convierten, en su conjunto, en el primer donante mundial-, como por su objetivo de convertirse en socio en el desarrollo y, con ello, ejercer la cooperación en el marco de la gobernanza global. Sin embargo, existen varias amenazas y riesgos que ponen en cuestión los avances conseguidos; entre ellos cabe destacar la forma en la que la cooperación para el desarrollo queda articulada en la acción exterior que diseña el Tratado de Lisboa, la atención prioritaria europea a los efectos de la crisis económica y, como telón de fondo, la deriva conservadora que va tomando la Unión en su conjunto, en consonancia con lo que sucede en los países miembros.

Palabras clave: Unión Europea, relaciones exteriores, cooperación para el desarrollo, gobernanza y desarrollo.

Abstract: Cooperation for development is one of the most important assets of the European Union presence in the world. It has progressively consolidated, so that nowadays it has become of the most important actors of Official Development Assistance (ODA), as much for its contributions - which make it, as a whole, the world's largest donor-, as for its aim of becoming a partner in the development and thereby implementing cooperation in the framework of global governance. However, there are several threats and risks that challenge the progress achieved; among them, it is worth mentioning the way in which development cooperation is articulated in the external action designed by the Lisbon Treaty, the European priority interest focused on the effects of the economic crisis and, be- 
hind this, the conservative drift that the EU is taking as a whole, in line with what is happening inside the member countries.

Keywords: European Union, external relations, development cooperation, governance and development.

\section{Introducción}

La Unión Europea se ha convertido ya en un actor global, si bien es cierto que en algunas dimensiones todavía no ha alcanzado un desarrollo pleno y, por tanto, un reconocimiento pleno.

En el ciclo vital de la integración europea, hemos asistido crónicamente a una oscilación entre la alegría por los éxitos logrados y el europesimismo, en aquellos momentos en los que parece que la Unión Europea no está a la altura de las circunstancias. Cualquiera que se asome a los medios de comunicación en los últimos meses verá que el catálogo de adjetivos dedicados a su situación no deja lugar a muchas dudas: incapacidad, debilidad, escasa credibilidad, insuficiencia, parálisis.

La escasa -o, en su caso tardía - respuesta europea ante el cúmulo de situaciones a las que ha tenido que hacer frente en los últimos tiempos pone en evidencia que todavía en bastantes ocasiones la UE como tal no dispone de las políticas ni de los recursos necesarios para atenderlos suficientemente. No deja de ser curioso que ahora que tenemos más Europa en los Tratados - especialmente con el de Lisboa-, parece que tenemos menos Europa en la realidad. Dicho de otro modo, la percepción es que cuando las situaciones se complican, los Estados vuelven a adquirir un protagonismo, en detrimento del que debe corresponderle a la Europa (no $\tan )$ unida.

Son muchos los casos donde se escenifica ese hecho, pero centraremos este texto en el papel que le corresponde a la cooperación para el desarrollo, como uno de los activos más importantes de la acción exterior de la Unión Europea, como parte de un conjunto de políticas (económicas, políticas, en materia educativa o en el ámbito del medio ambiente).

Para ello trazamos un recorrido que arranca con un repaso a la situación de la cooperación para el desarrollo que realiza la Unión y que continúa con el examen a cómo se vincula a la política exterior europea. A partir de ahí, se examina con detalle la política y la gestión de la ayuda europea, haciendo referencia especialmente a la ya consolidada doctrina europea sobre este ámbito. Lo que nos lleva a continuación a comprobar cuál es el papel de la cooperación europea en el mundo y, como correlato, a 
analizar cuál es su aportación, desde su política de cooperación, a la gobernanza global y, mirando al futuro, cuáles son los riesgos y amenazas que se ciernen sobre una mayor y mejor política europea de cooperación para el desarrollo.

Partimos de la consideración de que las políticas de cooperación son un activo del llamado «poder blando» ${ }^{1}$ que incluye, en el caso de la Unión Europea, el poder de convicción más que la amenaza o el uso de la fuerza, los dispositivos de naturaleza preventiva más que el intervencionismo, el recurso a la diplomacia - complementada con medidas comerciales, de ayuda y fuerzas de paz - para solucionar los conflictos y procurar el entendimiento a escala internacional.

Sin embargo, como sucede en un proceso inacabado, dentro de la Unión hay políticas con repercusión exterior que se solapan, no están coordinadas y, como consecuencia, no garantizan la aplicación del principio de coherencia, ni maximizan el potencial que la Unión debería desplegar si actuara como un solo actor. El panel de políticas con dimensión externa es amplio (ayuda humanitaria, comercio exterior, derechos humanos, desarrollo y cooperación, política exterior y de seguridad, relaciones exteriores, y otras de carácter transnacional como el medio ambiente), lo que redunda en la complejidad de su puesta en común. En aras del pragmatismo, hay que reconocer los sustanciales avances de la Unión en materia de política exterior y, como no, la dificultad de poner en común ámbitos competenciales que son considerados como parte del núcleo duro de la soberanía estatal.

\section{Breve diagnóstico sobre el estado de la cooperación para el desarrollo}

Si hay un terreno en el que podemos ver el alcance de la puesta en escena de la contribución de la gobernanza global por parte de la UE, ese es el de la cooperación para el desarrollo. Indudablemente no es el único, pero sí uno de los más significativos. Entre otras cosas porque en él se

1 Término acuñado por el profesor de la Universidad de Harvard Joseph S. Nye, especialmente por medio de su obra Soft Power: The Means to Success in World Politics, publicada en 2004. Su último libro, publicado en 2011, lleva por título The Future of Power. Nye ve a la Unión Europea, con todas sus dificultades en el proceso de integración, como lo más parecido a Estados Unidos a la hora de establecer nuevos líderes mundiales. No es de la misma opinión Robert Kagan, calificado como uno de los intelectuales de la derecha estadounidense, quien en Poder y debilidad: Europa y Estados Unidos en el nuevo orden mundial, publicada en 2003, viene a identificar a Estados Unidos con Marte (poder, interés nacional, guerra justificada), mientras que la UE sería Venus (idealismo, diplomacia, respeto al derecho). 
determina la toma de posición entre valores e intereses, y demuestra en la práctica en alcance de la solidaridad europea con los países más desfavorecidos. La premisa es que, tradicionalmente, cuantos más intereses tiene un actor, rebaja el alcance de la puesta en práctica de sus valores. Si la Unión quiere mantener en el futuro su opción a ser un socio en el desarrollo, tendrá que aquilatar la consolidación de su política de cooperación, con la práctica de otras políticas que mantengan la coherencia con el desarrollo.

Comencemos resaltando que la UE hace gala de que es el primer donante mundial de ayuda oficial al desarrollo, lo que es cierto si sumamos las ayudas de cada Estado miembro a la que concede la propia UE. Según los datos del Comité de Ayuda al Desarrollo (CAD), en 2010 las instituciones europeas destinaron a Ayuda Oficial al Desarrollo (AOD) un total de 12.986 millones de dólares; la AOD de los 15 países miembros de la UE que forman parte del CAD es de 70.150 millones de dólares. Lo que suma un total de 83.136 millones de dólares. En cuanto al porcentaje que supone la ayuda de los países europeos respecto al PIB, pasó del 0,44\% en 2009 al 0,46\% en 2010. La AOD total del conjunto de los países miembros del CAD fue de 128.728 millones de dólares.

No obstante, dentro de los países europeos la situación es muy variada $\mathrm{y}$, en función de circunstancias internas - especialmente por el mayor o menor impacto de la crisis - hay aumentos y reducciones, en muchos casos bastante significativos. Así algunos de ellos registraron un considerable aumento de la AOD, como es el caso de Portugal (un 31,5\% más por el aumento de los préstamos bilaterales), Reino Unido (un 19,4\% más), Bélgica (un 19,1\%), Alemania (9,9\%), Austria (8,8\%), Francia (7,3\%), Finlandia $(6,9 \%)$, Dinamarca $(4,3 \%)$ y Países Bajos $(2,2 \%)$. Sin embargo, otros países han disminuido significativamente su ayuda, como en los casos de Grecia (un 16,2\% menos por los problemas fiscales del país), Suecia (un 7,1\% menos, aunque el país sigue destinando alrededor del $1 \%$ de su PIB), Irlanda (4,9\% por los problemas fiscales), Italia (1,5\%) y Luxemburgo $(0,3 \%)$.

España destinó en 2010, según los datos de la OCDE, 5.917 millones de dólares (4.127 millones de euros), lo que constituye el 0,43\% del PIB español. Esta ayuda, según el organismo económico, es un 5,9 por ciento inferior a la de 2009, un descenso que atribuye a la «presión presupuestaria».

Los datos completos pueden verse en el siguiente cuadro: 


\section{Tabla 1}

Net official development assistance in 2010

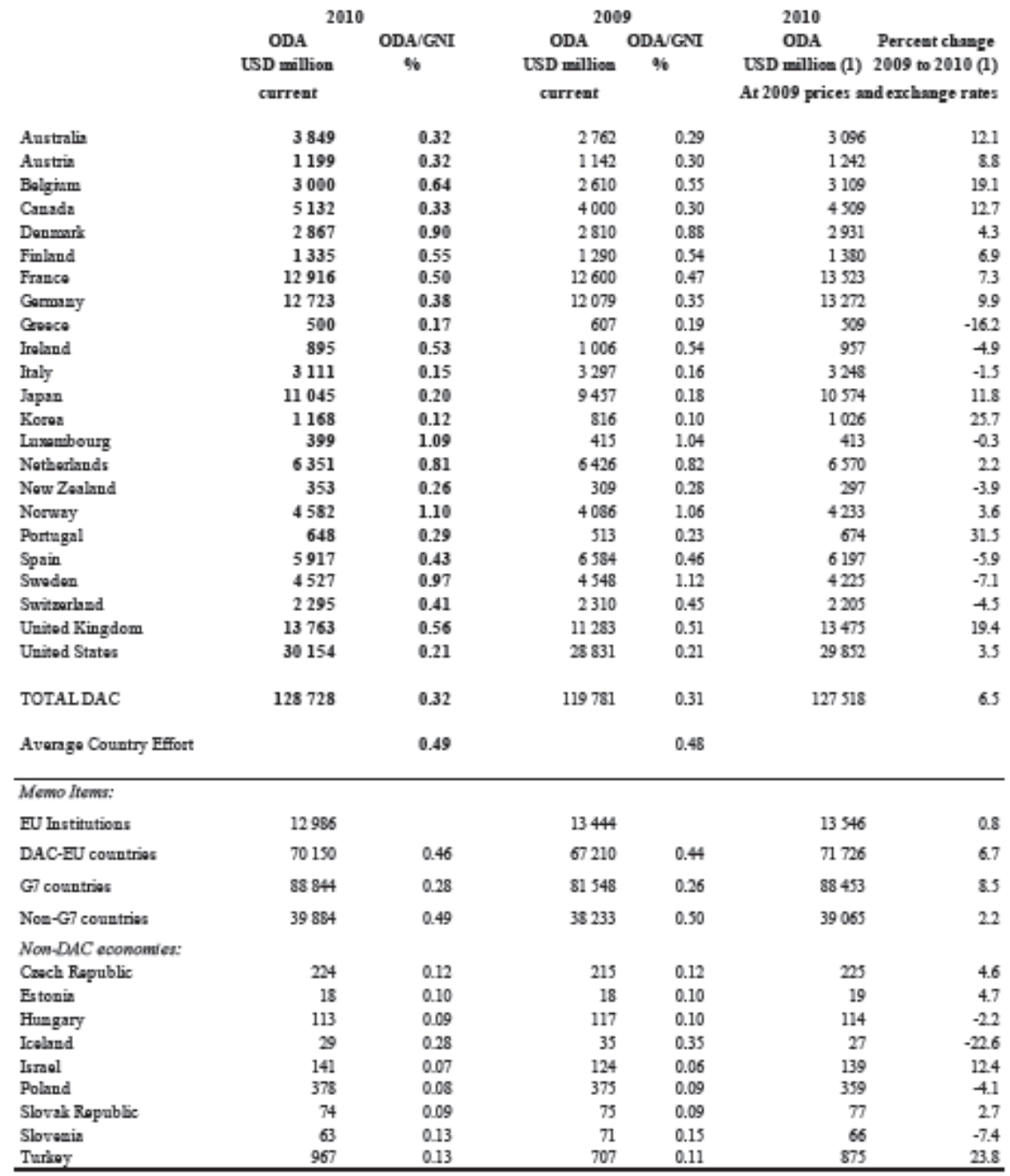

Fuente: Comité de Ayuda al Desarrollo

Además de ser el principal aportador de fondos, la UE no quiere limitarse a «suministrar servicios de primera necesidad como agua potable o carreteras asfaltadas. La UE utiliza también el comercio para impulsar el desarrollo, abriendo sus mercados a las exportaciones procedentes de 
los países pobres y animando a éstos a que comercien más entre sí», según la propia expresión que utiliza la UE para definir el alcance de esta política.

La construcción de la política europea de cooperación se ha ido elaborando progresivamente, desde una dimensión fundamentalmente postcolonial (que tiene en las antiguas colonias de países europeas - hoy países de África, Caribe y Pacífico- el principal destino de la ayuda de la propia UE), para ampliarse a la Política Europea de Vecindad, junto a la cooperación con países asiáticos y latinoamericanos. Es dimensión regional se combina con el apoyo europeo al multilateralismo, y muy especialmente a la consecución de los Objetivos de Desarrollo del Milenio, y a la presencia europea en los foros y citas internacionales donde se adoptan los compromisos en aras de mejorar la calidad de la ayuda, como la Declaración de Paris sobre la eficacia de la ayuda y el Programa de Acción de Accra.

Por otro lado, la crisis económico-financiera global impacta significativamente en Europa, lo que conduce a varios efectos: la pérdida de credibilidad (si la economía integrada era más fuerte, ¿por qué es tan débil?), lo que lleva a alentar incluso que algunos países salgan del euro; como correlato a lo anterior, se observa la escasa gobernanza económica europea, que queda en segundo término ante las opciones nacionales y la fortaleza alemana; un cierto ensimismamiento, ¿cómo vamos a liderar el mundo si estamos tan mal dentro? Por supuesto, otro indicador será cómo impacta la crisis en los fondos destinados a cooperación: si nos hace falta ¿por qué darlo a los demás? Aunque las comparaciones sean odiosas, en 2010 las instituciones europeas destinaron a ayuda al desarrollo 12.986 millones de dólares (unos 9.100 millones de euros); las cifras que se manejan para rescatar a algunas de las deprimidas economías de países miembros de la Unión son significativas: Portugal (unos 78.000 millones de euros), Grecia (unos 110.000 millones). ¿Cómo afectará esa solidaridad interna a la solidaridad internacional de la UE?

Se conforma así una política de cooperación, que en cierta medida se realiza de manera autónoma, pero que tiene que insertarse en el complejo tablero de la política exterior europea.

\section{Política exterior y cooperación en la Unión Europea}

El camino de la integración europea que, recordemos, tiene como misión la unión cada vez más estrecha entre los pueblos de Europa, ha seguido dos vías: el de la integración económica y el de la política. La primera ha avanzado sustancialmente, llegando a conformar, de manera incompleta todavía, una unión económica y monetaria, que tiene en el euro su representación más gráfica. 
No han ido a la par los avances en integración política, puesto que la integración en este campo es más compleja por su propia naturaleza, ya que afecta a terrenos considerados como del núcleo duro de la soberanía estatal y, por tanto, en ellos es más difícil de aplicar la «alquimia política» de la que nos habla Mark Leonard²: «Cada país perseguirá su interés nacional, pero una vez los diferentes intereses nacionales se introdujeran en la caja negra de la integración europea, por el extremo opuesto aparecería un proyecto europeo ... los Estados miembros se han esforzado por llegar a un acuerdo sobre su destino final y han buscado refugio en procesos que reflejan los valores europeos. Irónicamente, han escogido proyectar sus valores a nivel europeo con el fin de defender sus intereses a nivel nacional. Esto genera una peculiar situación que las naciones se preocupan por sus intereses y no por sus valores y la Unión europea por los valores pero no por los intereses.»

El fin de la Guerra Fría, el fin de la división europea y la recuperación de los valores de la integración, y la necesidad de poner en activo uno de los principios de esa integración, que Europa hable con una sola voz en el mundo, hace necesario dotar a la UE de una política exterior, más aún en un mundo complejo y turbulento.

Siempre a ritmo lento, la UE se va incorporando una filosofía, un método de trabajo, una doctrina, unas políticas, unos instrumentos y unos recursos que dan vida progresivamente a esa voz propia en la escena internacional.

El Tratado de Maastricht supone un primer paso fundamental, al incluir disposiciones relativas a la política exterior y de seguridad común, que se ha ido completando en tiempos más cercanos con otros.

La fallida Constitución Europea dio paso al Tratado de Lisboa y en ese itinerario uno de los aspectos más debatidos fue el de qué política exterior debería tener una Unión Europea que aspirara a tener un papel importante en el mundo globalizado; por ende, en función de ese modelo, habría que incorporar una política de cooperación que se va consolidando con el paso del tiempo.

Sintetizando, encontramos la elaboración de un buen diseño doctrinal, que tiene como base el ejercicio de una política de responsabilidad ${ }^{3}$. Uno de los textos que mejor reflejan esa opción europea es la Declaración de Laeken, con el significativo título de «El futuro de la Unión Europea», adoptado

2 Véase LEONARD, M., Por qué Europa liderará el siglo XXI, Madrid, Taurus, 2005.

${ }^{3}$ Sobre la política de responsabilidad en el marco de la acción exterior europea, ver el libro de ALDECOA, F., GUINEA, M., La Europa que viene: el Tratado de Lisboa, Madrid, Marcial Pons, diciembre de 2009, segunda edición. Sobre la política exterior de la Unión Europea, ver la obra de KEUKELEIRE, S., MACNAUGHTAN, J., The Foreign Policy of European Union, Basingstoke, Palgrave MacMillan, 2008. 
el 15 de diciembre de 2001. No está nada mal que nuestros jefes de Estado o de Gobierno reflexionen sobre este asunto y se planteen preguntas como ¿cuál es el papel de Europa en este mundo transformado? ¿no debería Europa, ahora por fin unificada, desempeñar un papel de liderazgo en un nuevo orden planetario, el de una potencia a la vez capaz de desempeñar una función estabilizadora a nivel mundial y de ser punto de referencia para numerosos países y pueblos? La respuesta es que «Europa debe asumir su responsabilidad en la gobernanza de la globalización». Para ello, la Unión debe aspirar a ser «una potencia que quiere hacer evolucionar las relaciones en el mundo de manera que no sólo beneficien a los países ricos sino también a los más pobres. Una potencia que quiere enmarcar éticamente la mundialización, es decir, ligarla a la solidaridad y al desarrollo sostenible».

Para convertirse en un actor global, como otros actores, la Unión se dota de un documento de estrategia que perfila sobre qué principios, qué objetivos y cómo se pone en marcha su política exterior. Ese documento es la Estrategia de Seguridad, que tiene un título muy significativo: «Una Europa segura en un mundo mejor», adoptado el 12 de diciembre de 2003, bajo la batuta de Javier Solana, conocido como mister PESC. La Estrategia nace bajo los efectos de los atentados terroristas del 11 de septiembre de 2001 y se va revisando periódicamente.

Es muy importante destacar el enfoque que la Estrategia da a la seguridad, que sobrepasa sus elementos más tradicionales (vincularla, por ejemplo, exclusivamente a cuestiones militares) para ampliar la dimensión seguridad a ámbitos como el medio ambiente o la pobreza. Las amenazas, por tanto, no son solamente tradicionales (armas de destrucción masiva, por ejemplo), sino que abarcan elementos como el cambio climático o la pobreza. De ello se deriva que hay que actuar con armas tradicionales frente a amenazas tradicionales, pero que hay que actuar de otra manera frente a esas otras amenazas. La prevención se convierte en un elemento central a la hora de minimizar la potencialidad de los conflictos. Por tanto, la cooperación es la mejor forma de actuar para reforzar los vínculos con otros actores y tratar asuntos de interés común, y la solidaridad es el ejercicio por el cual la Unión Europea colabora con los países más necesitados.

Dejemos que sea el propio texto de la Estrategia el que explicite qué papel le corresponde a la Unión en el mundo:

«La creciente convergencia de los intereses europeos y el fortalecimiento de la solidaridad dentro de la UE convierten a la Unión Europea en un actor más creíble y eficaz. Europa tiene que estar dispuesta a asumir su responsabilidad en el mantenimiento de la seguridad mundial y la construcción de un mundo mejor.

En gran parte del mundo en desarrollo, la pobreza y la enfermedad causan indecibles sufrimientos y provocan una apremiante sensación de 
inseguridad. Casi tres mil millones de personas, la mitad de la población mundial, viven con menos de dos euros diarios. Cuarenta y cinco millones mueren cada año de hambre y malnutrición. El sida es hoy una de las pandemias más devastadoras de la historia de la humanidad y un factor de fractura social. Las nuevas enfermedades pueden propagarse con rapidez y convertirse en amenazas de ámbito mundial. El África subsahariana es hoy más pobre que hace diez años. En muchos casos, el fracaso económico está ligado a problemas políticos y a conflictos violentos.

La seguridad es una condición para el desarrollo. El conflicto no sólo destruye las infraestructuras, incluidas las sociales, sino que también fomenta la delincuencia, disuade a los inversores e imposibilita la actividad económica normal. Varios países y regiones han quedado atrapados en un ciclo de conflicto, inseguridad y pobreza.

Las políticas de comercio y desarrollo pueden ser un poderoso instrumento para promover la reforma. La Unión Europea y sus Estados miembros, que son el mayor donante de asistencia oficial del mundo y su mayor entidad comercial, están en una situación idónea para promover estos objetivos.

La contribución a una mejor gobernanza mediante programas de asistencia, la imposición de condiciones y unas medidas comerciales específicas sigue siendo un elemento importante de nuestra política, que debemos reforzar aún más. La sensación de vivir en un mundo que ofrece justicia y oportunidades a todos incrementará la seguridad de la Unión Europea y de sus ciudadanos.

Más coherentes. La clave de la Política Exterior y de Seguridad Común y de la Política Europea de Seguridad y Defensa consiste en que juntos somos más fuertes. A lo largo de los últimos años hemos ido creando una serie de instrumentos, cada uno con su propia estructura y su propio fundamento.

El desafío actual consiste en reunir los distintos instrumentos y capacidades: los programas de asistencia europeos y el Fondo Europeo de Desarrollo, las capacidades militares y civiles de los Estados miembros y otros instrumentos. Todos ellos pueden influir en nuestra seguridad y en la de terceros países. La seguridad es la primera condición del desarro110 .

La labor diplomática y las políticas de desarrollo, comercio y medio ambiente deberían seguir el mismo esquema. En una crisis la unidad de mando es insustituible.

Conclusión: Vivimos en un mundo con nuevos peligros pero también con nuevas oportunidades. Dado su potencial, la Unión Europea puede contribuir de forma decisiva a afrontar las amenazas y a materializar las oportunidades. Una Unión Europea activa y capaz tendría la influencia que le corresponde en la escena internacional y contribuiría así a un sistema multilateral efectivo que condujera a un mundo más justo, más seguro y más unido». 
El último paso, por ahora, en el proceso de integración europea, el Tratado de Lisboa, regula, en el punto 5 del artículo 3, que

«En sus relaciones con el resto del mundo, la Unión afirmará y promoverá sus valores e intereses y contribuirá a la protección de sus ciudadanos. Contribuirá a la paz, la seguridad, el desarrollo sostenible del planeta, la solidaridad y el respeto mutuo entre los pueblos, el comercio libre y justo, la erradicación de la pobreza y la protección de los derechos humanos, especialmente los derechos del niño, así como al estricto respeto y al desarrollo del Derecho internacional, en particular el respeto de los principios de la Carta de las Naciones Unidas».

Por otro lado, el reconocimiento internacional de la Unión Europea sigue avanzando, como lo demuestra el hecho de que la Asamblea General de las Naciones Unidas acordara, el 3 de mayo de 2011, permitir a sus representantes (Van Rompuy y Ashton) presentar y promover las posiciones de la UE en Naciones Unidas, eso sí, conforme a lo acordado con los Estados miembros. Un paso pequeño, pero muy importante. También es cierto que cuando la canciller alemana Angela Merkel visita Estados Unidos y se entrevista con el presidente Obama (6 de junio de 2011), algunos medios la califican como la presidenta de hecho de la Unión Europea.

Encontramos, pues, todo un cuerpo normativo, el deber ser propio de una comunidad jurídico-política, que encamina a la Unión Europea hacia un modelo de presencia internacional, que promueve como principio básico trasladar al exterior su propia naturaleza, en el sentido de promover la solidaridad no sólo como un ideal, sino dotándola de los medios necesarios para conseguir su ejercicio efectivo. Sin embargo, ese deber ser se enfrenta a toda una serie de obstáculos que impiden su cumplimiento.

Antes de llegar a ellos, veamos los aspectos más sustanciales de la política europea de cooperación, examinando su doctrina principal y los elementos que definen su política y gestión.

El escenario no es muy alentador, y surgen voces que advierten de un posible declive europeo como actor global. Entre ellos, Richard Youngs ${ }^{4}$ ofrece una crítica de cómo Europa está afrontando su pérdida de poder en el escenario internacional y analiza las respuestas europeas a la crisis financiera, el mundo multipolar emergente, los nuevos desafíos de seguridad, las cuestiones relativas a la identidad europea y la situación de los derechos humanos en el mundo.

${ }^{4}$ Véase YOUNGS, R., Europe's Decline and Fall. The struggle against global irrelevance, Londres, Profile Books Limited, 2010. 


\section{El papel de la Unión Europea en la cooperación para el desarrollo}

Comentábamos antes que los inicios de la política europea de cooperación hay que situarlos cuando desde la Unión se activan ayudas al desarrollo, en el sentido más tradicional del término, hacia países que dejan de ser colonias europeas para convertirse en Estados formalmente independientes. La ayuda, en buena medida, servirá de instrumento al servicio de una relación neocolonial (todavía se mantiene en los Tratados la asociación de los países y territorios de Ultramar).

Ese hecho fundacional de la ayuda europea - su pecado original en alguna medida - marcará toda su historia hasta nuestros días. Pero obviamente, la política europea en este ámbito sufrirá transformaciones para adecuarla a los cambios que vive la propia Unión - en tensión constante entre consolidación, ampliación y profundización -, los países subdesarrollados - con toda su heterogeneidad - y el propio contexto internacional - sobre el que no hay acuerdo en torno a la nueva naturaleza de poder que lo configura - .

\section{La doctrina europea sobre la cooperación para el desarrollo ${ }^{5}$}

Tras una serie de actividades que van dando cuerpo a una ayuda al desarrollo sin política, en el último decenio se va tejiendo paulatinamente la estructura de una política de cooperación para el desarrollo, que se conforma a base de una serie de documentos que fijan la doctrina sobre esta materia, que conducirá a la adopción de unas normas - o la celebración de acuerdos de cooperación - que harán operativa esa doctrina. Es muy importante subrayar el trabajo conjunto de Comisión Europea, Parlamento Europeo y Consejo y, especialmente, es necesario resaltar el apoyo de la ciudadanía europea a la solidaridad internacional, como demuestran periódicamente las encuestas recogidas en el Eurobarómetro.

A partir del año 2000, por tanto, se redefine la política de cooperación de la Unión Europea, para consagrarla como una política propia, articulando tanto sus contenidos en función de unos objetivos y unas prioridades regionales y sectoriales, así como estableciendo un entramado institucional que la lleve a la práctica.

${ }^{5}$ Entre la bibliografía sobre este tema, ver la obra de SOTILLO, J.A., Un lugar en el mundo. La política de desarrollo de la Unión Europea, Madrid, IUDC - Los Libros de la Catarata, 2006 y la de GRANELL, F., La coopération au développement de la Communauté Européenne, Institut d'Etudes Européennes de l'Université de Bruxelles (Collection Commentaire J. Megret), 2005. 
Los pasos más importantes que visibilizan ese recorrido son el Consenso Europeo sobre Desarrollo (2005), el Instrumento de financiación de la cooperación al desarrollo (2006), el Código de conducta sobre la complementariedad y la división de trabajo en la política de desarrollo (2007), hasta llegar al Tratado de Lisboa. Por supuesto, la $\mathrm{UE}^{6}$ va incorporando toda una serie de normas y compromisos, que van constituyendo el acervo de la cooperación europea, de los que destacaremos aquellos más directamente relacionados con la gobernanza. Recordemos que ese recorrido temporal tiene en paralelo la reforma de la arquitectura de la ayuda, escenificada en la Declaración de París (2005).

El texto programático más importante de la política de desarrollo de la UE es el Consenso Europeo sobre Desarrollo ${ }^{7}$, adoptado conjuntamente por la Comisión, el Consejo y el Parlamento Europeo el 20 diciembre 2005. Con respecto a la vinculación entre gobernanza y desarrollo, el documento reitera que «el desarrollo constituye un objetivo central en sí mismo, y que un desarrollo sostenible abarca cuestiones de gobernanza, derechos humanos, así como aspectos políticos, económicos, sociales y ambientales».

En concreto, en el punto 86 establece que

«El progreso en materia de protección de los derechos humanos, el buen gobierno y la democratización son fundamentales para la reducción de la pobreza y el desarrollo sostenible (1). Todas las personas deberían gozar de todos los derechos humanos a tenor de los acuerdos internacionales. Atendiendo a esto, la Comunidad fomentará el respeto de los derechos humanos de todas las personas en cooperación tanto con los Estados como con los agentes no estatales de los países socios. La Comunidad se esforzará en promover activamente los derechos humanos como parte integrante de un diálogo participativo dentro de cada país relativo a la buena gobernanza. El fomento de la buena gobernanza exige un planteamiento pragmático basado en el contexto particular de cada país. La Comunidad promoverá activamente un diálogo participativo dentro de cada país relativo a la buena gobernanza en ámbitos como la lucha contra la corrupción, la reforma del sector público, el acceso a la justicia y la reforma del sistema judicial. Esto es esencial para la puesta en marcha de programas de reforma orientados en función de la situación de cada país en un contexto de asunción de responsabilidades y en un entorno institucional respetuoso de los derechos humanos, los principios democráticos y el Estado de derecho».

${ }^{6}$ Desde la página de la Unión Europea se puede realizar la consulta y el seguimiento de la política de desarrollo y cooperación, http://europa.eu/pol/dev/index_es.htm. Ver también el Atlas de la UE como donante en 2011, en http://development.donoratlas.eu/home.html

7 Diario Oficial C 46, de 24.2.2006. 
A partir de la estrategia definida por el Consenso, se han venido adoptando toda una serie de disposiciones que completan el mapa de la cooperación europea, en consonancia con los cambios que está teniendo el propio sistema global de cooperación para el desarrollo.

Así, el Reglamento (CE) n. ${ }^{\circ}$ 1905/2006 del Parlamento Europeo y del Consejo, de 18 de diciembre de $2006^{8}$, establece un Instrumento de Financiación de la Cooperación al Desarrollo. El Reglamento destaca que la política de cooperación al desarrollo de la Comunidad se guía por los Objetivos de Desarrollo del Milenio (ODM), y que el marco general de actuación de la Comunidad en materia de desarrollo está determinado por el Consenso europeo. Reitera, además, que los objetivos de dicha política consisten en la reducción de la pobreza, el desarrollo económico y social sostenible y la inserción progresiva y armoniosa de los países en desarrollo en la economía mundial.

Los programas geográficos establecidos por el Reglamento engloban la cooperación con países y regiones socios determinados con arreglo a un criterio geográfico, y abarcan cinco regiones: América Latina, Asia, Asia Central, Oriente Medio y Sudáfrica. La ayuda comunitaria a favor de estos países está destinada a apoyar acciones en los siguientes ámbitos de cooperación: apoyo a la ejecución de medidas cuyo objetivo sea la erradicación de la pobreza y la consecución de los ODM; atención a las necesidades esenciales de la población y, en particular, la educación primaria y la sanidad; fomento de la cohesión social y del empleo; promoción del buen gobierno, la democracia y los derechos humanos, y apoyo a las reformas institucionales; asistencia a los países y regiones socios en los ámbitos del comercio y la integración regional; fomento del desarrollo sostenible por medio de la protección del medio ambiente y la gestión sostenible de los recursos naturales; apoyo a la gestión sostenible integrada de los recursos hídricos y fomento de un mayor uso de tecnologías energéticamente sostenibles; asistencia en las situaciones consecutivas a las crisis, y a los Estados frágiles.

Por su parte, los programas temáticos son el complemento de los programas geográficos. Estos programas tratan un ámbito de actividad específico que interese a un conjunto de países socios no determinado por criterios geográficos, o cubren actividades de cooperación dirigidas a distintas regiones o grupos de países socios, o una actuación internacional sin base geográfica específica. El Reglamento establece cinco programas temáticos que se refieren a: inversión en las personas; medio ambiente y gestión sostenible de los recursos naturales; agentes no estatales y autoridades locales; estrategia en favor de la seguridad alimentaria; cooperación en materia de migración y asilo.

${ }^{8}$ Diario Oficial L 378, de 27.12.2006. 
Otro texto de referencia es el Código de conducta sobre la complementariedad y la división de trabajo en la política de desarrollo ${ }^{9}$ ( 28 de febrero de 2007). Como código de conducta es voluntario y tiene como finalidad mejorar la distribución de las tareas entre los donantes de la UE en los países en desarrollo. Para ello,

«el código se basa en once principios destinados a reducir los trámites administrativos, utilizar los fondos donde sean más necesarios, poner en común la ayuda y distribuir las tareas para proporcionar mayor ayuda, más rápida y más eficaz. El código propone las directrices generales por las que se fijan los principios de la complementariedad en la ayuda al desarrollo, desde once principios rectores: 1 . Concentrar las actividades en un número limitado de sectores nacionales (sectores prioritarios): los donantes de la UE deberían limitar sus intervenciones en un país socio a los dos sectores para los que presenten la mejor ventaja comparativa en opinión tanto del Gobierno del país socio como de los demás donantes; además de dichos dos sectores, los donantes podrán proporcionar ayuda presupuestaria y financiar programas relativos a la sociedad civil, la investigación o la educación; 2. Reorganizar las demás actividades en el país (sectores no prioritarios): por lo que se refiere a los sectores no prioritarios, los donantes deberían mantener su intervención mediante acuerdos de cooperación o asociación delegada, bien transformando los recursos liberados en ayuda al presupuesto general, bien retirándose de forma responsable; 3 . Fomentar que, en cada sector prioritario, se celebre un acuerdo de donante principal, responsable de la coordinación entre todos los donantes del sector, con el fin de reducir los costes de transacción; 4. Fomentar la celebración de acuerdos de cooperación o asociación delegada, por los cuales un donante tiene la capacidad de actuar en nombre de otros donantes en cuanto a la administración de fondos y el diálogo con el Gobierno socio sobre la política que debe aplicarse en el sector en cuestión; 5. Garantizar el apoyo adecuado en los sectores estratégicos: un donante de la UE, por lo menos, debería participar activamente en cada sector estratégico considerado pertinente para reducir la pobreza; además, el número de donantes activos debería limitarse, como máximo, a entre tres y cinco donantes por sector; 6 . Reproducir esta práctica de división del trabajo a escala regional, mediante la aplicación, a nivel nacional, de los principios de división del trabajo en el ámbito de la colaboración con los demás organismos regionales asociados; 7. Designar un número limitado de países prioritarios para cada donante, a través de un diálogo en la UE; 8. Conceder financiación adecuada a los países descuidados por la ayuda, que suelen ser países frágiles cuya estabilización tiene un efecto colateral positivo en la región; 9. Analizar y ampliar los ámbitos de competencia: los donantes de la UE deberían profundizar las autoevaluaciones de sus

9 COM (2007) 72 final, Bruselas, 28.2.2007. 
ventajas comparativas con el fin de especializarse en mayor medida; 10. Seguir ahondando en otros aspectos de la complementariedad, como la complementariedad vertical y entre formas e instrumentos de ayuda; 11 . Profundizar las reformas de los sistemas de ayuda: los cambios sugeridos por el código requieren reformas y cambios estructurales, y tendrán consecuencias en términos de personal».

La Unión Europea cuenta, pues, con todo un conjunto de normas y procedimientos que intentan garantizar la coordinación, la coherencia y la complementariedad de la política de cooperación tanto en el escenario interno (con respecto a los países miembros), como en su puesta en escena internacional. Con ello, se pretende contribuir a las mejoras en la calidad de la ayuda y, en consecuencia, a reforzar la vinculación entre gobernanza y desarrollo, promoviendo de forma constante que las medidas destinadas fundamentalmente a la lucha contra la pobreza y al cumplimiento de los ODM se realicen en un entorno de democracia, respeto a los derechos humanos y buen funcionamiento de las instituciones, con un protagonismo activo de la sociedad civil en los países en desarrollo.

Un hecho significativo se produjo cuando, por vez primera, el Consejo Europeo, bajo presidencia española, el 17 de junio de $2010^{10}$, incluía en su orden del día el apoyo a los Objetivos de Desarrollo del Milenio. En las conclusiones se afirma que

«La Unión Europea sigue resuelta a apoyar la consecución de los objetivos de desarrollo del milenio en el mundo en 2015. Esto es posible si todos los socios dan muestras de un firme compromiso político, aplican los necesarios cambios de política y actúan de modo concreto. La Unión Europea insta a la sesión plenaria de alto nivel a que apruebe acciones concretas con objeto de aumentar la responsabilización de los países en desarrollo, concentrar los esfuerzos, mejorar la incidencia de las políticas, movilizar más financiación y financiación más predecible para el desarro1lo, incluidas las fuentes de financiación innovadoras, y aprovechar más eficazmente los recursos de desarrollo. El Consejo Europeo reitera su compromiso de lograr los objetivos de la ayuda al desarrollo para 2015, como se establece en sus Conclusiones de junio de 2005. El Consejo Europeo conviene en volver a tratar esta cuestión cada año sobre la base de un informe del Consejo».

Ese importante ejercicio de voluntad política, se ve contrarrestado por la escasez de resultados, como se explica desde la Coordinadora ONG para

${ }^{10}$ Ver texto en http://www.consilium.europa.eu/uedocs/cms_data/docs/pressdata/es/ec/ 115349.pdf. 
el Desarrollo-España ${ }^{11}$ : «Para las ONGD europeas, el acuerdo anunciado por los 27 de alcanzar el $0,7 \%$ de la Renta Nacional Bruta de la UE para Ayuda Oficial al Desarrollo en 2015, no es suficiente si no viene acompañado de calendarios vinculantes de desembolsos de ayuda y actuaciones que respeten los compromisos asumidos de cantidad de ayuda para que dejen de pagar la crisis las personas más vulnerables» (en negrita en el original).

Con el fin de revisar sus planteamientos en materia de cooperación para el desarrollo, la Comisión ha lanzado el Libro Verde sobre «Política de desarrollo de la UE en apoyo del crecimiento integrador y el desarrollo sostenible. Mejorar el impacto de la política de desarrollo de la UE» ${ }^{12}$, que se critica por centrarse en la reforma de la gestión de la cooperación y no entrar en el debate sobre el modelo de desarrollo, más allá de que se insista en la senda del crecimiento económico como el camino que conduce directamente al desarrollo.

Para la Asociación Latinoamericana de Organizaciones de Promoción del Desarrollo (ALOP) ${ }^{13}$, «la idea presentada por la Comisión Europea sobre una «política de desarrollo de gran impacto» está relacionada con la agenda de la eficacia de la ayuda y el enfoque basado en resultados que en los últimos años han marcado el debate internacional sobre la cooperación al desarrollo. Este marco conceptual asume que existe un consenso respecto a los resultados buscados, o sea, «el desarrollo», y por lo tanto se enfoca en la eficacia de la ayuda y su impacto, donde es «la ayuda» el centro del debate y no «el desarrollo».

En todo caso, el documento, que nace abierto a la participación, deberá pasar por toda una serie de consultas antes de que la Comisión adopte la comunicación correspondiente.

Un grupo de «think tanks» ${ }^{14}$ ha señalado los próximos pasos en la cooperación europea para el desarrollo, comenzando por la revisión del Consenso Europeo sobre Desarrollo, en el marco de las novedades que incluye el Tratado de Lisboa. Como ejes principales de la consolidación de esa política se establecen: la primacía de la reducción de la pobreza; promover la coherencia de políticas; el cambio climático y desarrollo; paz, seguridad y

${ }^{11}$ Este y otros documentos se pueden consultar en www.urgeotraeuropa.org

12 COM (2010) 629 final, Bruselas, 10.11.2010.

13 El texto está disponible en http://www.alop.org.mx/content/brief-14-la-futurapol\%C3\%ADtica-de-cooperaci\%C3\%B3n.

${ }^{14}$ EUROPEAN THINK-TANKS GROUP, «Nuevos desafíos, un nuevo comienzo: Próximos pasos en la cooperación al desarrollo europea», febrero 2010. Se puede consultar desde la página de FRIDE: http://www.fride.org/publicacion/721/los-proximos-pasos-en-la-cooperacion-europea-al-desarrollo. 
conflicto; una política comercial favorable al desarrollo en inmundo postpreferencias; establecer relaciones con el sector privado; una política de migración favorable al desarrollo; el futuro de las asociaciones del desarrollo; la financiación al desarrollo de la UE; trabajar mejor en conjunto; una nueva agenda; el liderazgo de la UE en el pensamiento sobre la cooperación para el desarrollo; cobrar velocidad en la coherencia de políticas para el desarrollo; revigorizar las asociaciones del desarrollo; cumplir con las obligaciones de financiación y mejorar la selección de objetivos y la eficacia del gasto en materia de ayuda; y mejorar la coordinación entre los Estados miembros.

\section{Política y gestión de la cooperación europea}

Para implementar esa política que se refuerza progresivamente desde comienzos de 2000, la Unión Europea se va dotando gradualmente de un entramado institucional que buscará la mejora de la calidad de la ayuda y de aumentar la coherencia en las políticas de desarrollo. Esas loables intenciones, consagradas normativamente, tienen su techo de cristal en la naturaleza complementaria de la política europea de cooperación en relación a la que tienen cada uno de los Estados miembros, con lo cual la coordinación es fundamental para aumentar el impacto colectivo de la cooperación europea en su conjunto.

Un protagonismo central en EuropeAid, la Agencia europea de cooperación que depende de la Comisión Europea, y en concreto de la cartera de Desarrollo, a cuyo frente está el comisario Andris Piebalgs; junto a él está la comisaria de Cooperación Internacional, Ayuda Humanitaria y Protección Civil, Kristalina Georgieva. Las reformas que ha vivido la Unión en los últimos tiempos, sobre todo con el Tratado de Lisboa, refuerzan la política exterior y reordenan todo el entramado institucional. Si se fortalece la acción exterior de la Unión Europea, ¿cómo se incorpora a ella la política de cooperación? El Tratado de Lisboa, en aras de la simplificación, incorpora en el Tratado de Funcionamiento de la Unión Europea, el Título III, dedicado a «Cooperación con terceros países y ayuda humanitaria», con capítulos dedicados a «Cooperación para el desarrollo», «Cooperación económica, financiera y técnica con terceros países» y «Ayuda humanitaria».

Al mismo tiempo, la reforma de la acción exterior incluye las nuevas competencias del Alto Representante de la Unión para Asuntos Exteriores y Política de Seguridad (cargo desempeñado por Catherine Ashton), además de las que tiene como máximo representante al Presidente del Consejo Europeo (Herman van Rompuy). Y crea el Servicio Europeo de Acción Ex- 
terior (SEAE), que «constituye sin duda una de las innovaciones institucionales de mayor alcance político producidas en el seno del proceso de integración europea, desde sus orígenes hasta nuestros días» ${ }^{15}$.

Se da paso así a Desarrollo y Cooperación - EuropeAid ${ }^{16}$, como «nueva Dirección General responsable de las políticas de desarrollo de la UE y el suministro de ayuda a través de programas y proyectos en todo el mundo. Reúne las antiguas DG Desarrollo y EuropeAid. Una sola DG simplificará la comunicación en el ámbito del desarrollo actuando como «ventanilla única» para los interesados de la UE y de otros países». Sin embargo, la puesta en escena del SEAE está sembrando dudas con respecto a cuál va a ser su influencia con respecto a la política de cooperación, hasta ahora responsabilidad de la Comisión Europea, y sus dependencias de la política exterior europea ${ }^{17}$.

Habrá que ver, con el paso del tiempo, cómo se resuelve la tensión entre el reforzamiento de lo intergubernamental (Ashton es también vicepresidenta de la Comisión Europea) y el aumento de competencias de la Comisión Europea (y, por tanto, de entidades como EuropeAid). Estamos hablando también de espacios de poder dentro de un sistema burocráticoadministrativo, que pasa además por quién ocupa puestos de responsabilidad en ese sistema, que abre la pugna entre los países miembros para que sus nacionales desempeñen los más importantes.

Es importante también, para adecuar la Unión Europea a la cualidad de socio en el desarrollo, la puesta en marcha del proceso de desconcentración, por el cual adquieren un mayor protagonismo las delegaciones de la Comisión Europea en países terceros, como lugares de referencia para un mejor diseño de los proyectos y acciones de desarrollo.

\section{La cooperación europea en el mundo}

La cooperación europea ocupa ya un espacio propio en el conjunto del sistema de cooperación internacional. No sólo ya como el primer donante mundial de ayuda al desarrollo, sino con un protagonismo activo como re-

15 CORNAGO, N., GUINEA, M., «Repensar la diplomacia europea tras el Tratado de Lisboa: implicaciones del nuevo Servicio Europeo de Acción Exterior (SEAE)», Cuadernos Europeos de Deusto, núm. 44/2011.

16 Véase la página http://ec.europa.eu/europeaid/who/index_es.htm

17 GUINEA, M., «El Servicio Europeo de Acción Exterior: implicaciones para la Unión Europea como actor estructural de las relaciones internacionales», en El desarrollo del Tratado de Lisboa: un balance de la Presidencia española, obra dirigida por el profesor SOBRINO HEREDIA, J.M., Colección Escuela Diplomática, núm. 17, Madrid, 2011, p. 416. 
ferente superador de la ayuda al desarrollo basada en el asistencialismo y en el binomio donante-receptor.

El sistema europeo de cooperación tiene prácticamente una escala planetaria y cobra un especial significado en los casos de la ayuda humanitaria y de la rehabilitación post conflicto. Es cierto que hay casos donde esa ayuda europea no tiene la visibilidad necesaria, con lo cual la conclusión es que llega tarde y mal. Es el caso de Haití tras el terremoto del 12 de enero de 2010, donde los medios nos muestran la presencia casi inmediata de la secretaria de Estado de Estados Unidos (Hillary Clinton), mientras que la Alta Representante (Ashton) llegó el 3 de marzo. Pero casi siempre la ayuda europea supera a la de otros donantes; así, en el caso de Haití, la Comisión Europea ha anunciado la movilización de 100 millones de euros de un paquete de 300 millones que asignó para paliar las consecuencias del terremoto, que servirán para apoyar el inicio de la fase de reconstrucción del país.

Encontramos la reciente paradoja de cómo actúa la Unión Europea ante los cambios que están viviendo muchos países árabes, apoyando las transformaciones a la democracia, cuando poco tiempo antes buena parte de los dictadores de esos países eran socios privilegiados de la propia Unión Europea. Gadafi es ahora un dictador, y la Unión ha adoptado sanciones contra su régimen - además de que algunos Estados miembros participan en las acciones militares que la OTAN realiza contra el ejército libio-, pero el 29 y 30 de noviembre de 2010 fue el anfitrión de la Tercera Cumbre África Unión Europea; en Trípoli estuvieron presentes 80 jefes de Estado y de Gobierno, muchos de ellos más interesados en el gas libio que en la situación de la democracia y los derechos humanos. Muchos de ellos no recordarán que el tema de la convocatoria era «Inversión, crecimiento económico y creación de empleo» y que en la agenda europea una de las cuestiones a tratar fue la gobernanza y los derechos humanos.

Como antes mencionábamos, la Unión tiene delimitadas sus prioridades regionales, en función de distintos criterios, siendo las más importantes las relaciones con los países de África, Caribe y Pacífico (ACP), que son parte del Convenio de Cotonú (firmado el 23 de junio de 2000 por un período de 20 años), la Política Europea de Vecindad (canalizada, desde un diseño global, bilateralmente con cada uno de los países, principalmente con los países mediterráneos). Con el Instrumento de financiación se completa el mapa geográfico de la cooperación europea, al incluir a América Latina, Asia, Asia Central, Oriente Próximo y Sudáfrica.

Ese mapa se completa con las acciones de ámbito mundial como el apoyo a la consecución de los Objetivos de Desarrollo del Milenio, el Instrumento Europeo para la Democracia y los Derechos Humanos, la seguridad alimentaria, la inversión en las personas o el medio ambiente y la 
gestión sostenible de los recursos naturales. Un terreno muy difícil por todas sus complejidades es el de la cooperación en materia de migración y asilo.

Para rendir cuentas de esta política, se realizan evaluaciones de buena parte de las acciones emprendidas y todos los años la Comisión presenta un informe sobre las políticas de desarrollo y ayuda exterior y su aplicación ${ }^{18}$.

\section{La cooperación europea y la gobernanza global: riesgos y desafíos}

Más allá de la importancia que tienen las acciones contempladas como parte de la política de cooperación de la Unión Europea, el objetivo es que esa política sea una parte importante del ejercicio de gobernanza global que plantea la Unión, en el sentido de la política de responsabilidad dibujada en la Declaración de Laeken. Se trata, de nuevo, de trasladar (y compartir) al exterior lo que podemos considerar como el método europeo de gobernanza sin que, obviamente, se asuma como perfecto (como estamos comprobando con la actual crisis económica y política). Así lo expresa el Tratado de Lisboa: «la acción de la Unión en la escena internacional se basará en los principios que han inspirado su creación, desarrollo y ampliación».

En todo caso, la cuestión de la gobernanza (arte o manera de gobernar que se propone como objetivo el logro de un desarrollo económico, social e institucional duradero, promoviendo un sano equilibrio entre el Estado, la sociedad civil y el mercado de la economía, según el diccionario de la Real Academia Española) no es nueva para la Unión Europea; de hecho podemos afirmar que el método de la integración europea sea basa en la gobernanza, aunque esta palabra sea de uso más reciente.

El Consenso de Monterrey ${ }^{19}$ ya hacía alusión a la vinculación entre paz, democracia, derechos humanos, desarrollo y el buen funcionamiento de las instituciones:

${ }_{18}$ El informe correspondiente a 2009 está publicado en http://ec.europa.eu/europeaid/ multimedia/publications/documents/annual-reports/europeaid_annual_report_2010_ highlights_es.pdf. Se destaca que «En 2009, una vez más, la UE (los 27 Estados miembros y la Comisión Europea) fue el mayor proveedor de ayuda al desarrollo, aportando 48 200 millones de euros, es decir, más de la mitad de la ayuda oficial al desarrollo de todo el mundo; de esta cantidad, 10000 millones fueron desembolsados por la Comisión. Esto es algo de lo que podemos estar orgullosos, especialmente cuando constatamos los avances en la consecución de los Objetivos de Desarrollo del Milenio y en la lucha contra la pobreza.»

19 NACIONES UNIDAS, Conferencia Internacional sobre la financiación del desarrollo (Monterrey, México, 21 y 22 de marzo de 2002), A/Conf.198/3. 
«11. La buena gestión de los asuntos públicos es indispensable para un desarrollo sostenible. La aplicación de políticas económicas racionales, la existencia de instituciones democráticas sólidas que sepan responder a las necesidades de la población y el mejoramiento de la infraestructura constituyen la base de un crecimiento económico sostenido, de la eliminación de la pobreza y la creación de puestos de trabajo. La libertad, la paz y la seguridad, la estabilidad interna, el respeto de los derechos humanos, incluido el derecho al desarrollo, y el estado de derecho, la igualdad entre los géneros, las políticas con orientación de mercado y el compromiso general de crear sociedades justas y democráticas son también condiciones esenciales que se refuerzan mutuamente».

En el ámbito europeo, uno de los primeros pasos lo tenemos en el Informe de la Comisión sobre la gobernanza europea, COM (2002)705 de 11.12.2002, además del «Libro blanco sobre la gobernanza democrática».

En el Parlamento Europeo ${ }^{20}$ encontramos como entiende la Unión la relación entre gobernanza y desarrollo: «Considerando que el concepto de buena gobernanza es un factor determinante en la capacidad de un país de alcanzar un desarrollo sostenible desde el punto de vista económico, social y medioambiental; que dicho concepto va más allá de las nociones de derechos humanos, de Estado de Derecho y de democracia e incluye la administración eficaz y la lucha contra la corrupción y que, en último término, afecta a la capacidad del Estado para servir a los ciudadanos por medio de una gestión eficaz y transparente de los recursos humanos y naturales».

En el ámbito que nos ocupa, ya en la Comunicación de 20 de octubre de 2003 titulada «Gobernanza y desarrollo» se recoge la definición y el enfoque de la $\mathrm{CE}$ en materia de buen gobierno, «pese a no haber definición alguna de gobernanza que goce de aceptación general a nivel internacional»: «La gobernanza constituye un componente esencial de las políticas y reformas orientadas a la reducción de la pobreza, la democratización y la seguridad mundial. De ahí que el desarrollo de la capacidad institucional, especialmente de cara a la buena gobernanza y a la aplicación del Estado de Derecho, sea una de las seis vertientes de la política comunitaria de desarrollo a las que se concede una atención prioritaria en los programas de la $\mathrm{CE}$ en los países en desarrollo».

Un avance significativo está en la Comunicación de la Comisión, de 30 de agosto de 2006, titulada «La gobernanza en el consenso europeo sobre la política de desarrollo - Hacia un enfoque armonizado en la Unión Europea»

${ }^{20}$ Resolución del Parlamento Europeo sobre la gobernanza en la política de desarrollo de la Unión Europea (2003/2164(INI)), 31 de marzo de 2004. 
(COM (2006)0421): «En el marco del Consenso europeo sobre el desarrollo, la UE definió su planteamiento y sus medios de acción para contribuir a estos objetivos, definiendo, en particular, la buena gobernanza, la democracia y el respeto de los derechos humanos como componentes de pleno derecho del los procesos de desarrollo sostenible y de los objetivos importantes de la política de desarrollo de la UE. El aumento sustancial de los volúmenes de ayuda previsto para los próximos años requiere la implantación de una gobernanza que permita garantizar la eficacia y el impacto efectivo de este nuevo esfuerzo de ayuda europeo. Para lograr los ODM, sin embargo, no bastan los medios financieros».

En buena medida, las propuestas de la Comisión se recogen en el Reglamento (CE) 1889/2006 del Parlamento Europeo y del Consejo, de 20 de diciembre de 2006, por el que se establece un instrumento financiero para la promoción de la democracia y de los derechos humanos a escala mundial.

Donde vemos el contraste entre las opciones que se manejan y la realidad que sigue demostrando los escasos resultados conseguidos, es en el Código de Conducta relativo a la división del trabajo en el ámbito de la política de desarrollo (Bruselas, 28.2.2007-COM (2007) 72 final):

«Los ciudadanos europeos desean una Europa más fuerte, capaz de mejorar las condiciones de vida de la población más pobre del planeta; una Europa que luche contra la pobreza en el mundo de manera más fructífera, rápida y eficaz; una Europa que tenga más voz y una incidencia política acorde a su generosidad económica.

Pero los ciudadanos europeos también desean una Europa más eficaz y eficiente. En la última década, la multiplicación de actividades y estructuras de ayuda al desarrollo ha originado una compleja y costosa máquina. En cada país en desarrollo hay una media de 350 misiones de donantes al año. Hay una concentración excesiva de donantes en los mismos países y en los mismos sectores. En Mozambique, por ejemplo, hay al menos 27 donantes activos en la lucha contra el VIH. Como consecuencia de esta multiplicación, los países en desarrollo no suelen poder asimilar las numerosas misiones, los costes administrativos innecesarios, los solapamientos y duplicaciones, y los distintos requisitos, normas y condiciones de los donantes. Todo ello contribuye a reducir la transparencia y favorece la corrupción. Por el contrario, otros países, como la República Centroafricana o Somalia, son víctima del denominado "cansancio" de los donantes, y quedan prácticamente abandonados a su suerte».

Completando el triángulo Comisión-Parlamento Europeo-Consejo, contamos en el ámbito que nos ocupa con las Conclusiones del Consejo, de 18 
de mayo de 2009, sobre el apoyo a la gobernanza democrática - Hacia un marco mejorado de la UE.

En este recorrido, uno de los textos más importantes es la Resolución del Parlamento Europeo, de 22 de octubre de 2009, sobre la consolidación de la democracia en las relaciones exteriores de la UE. Recogemos dos de sus párrafos más significativos:

4. Reitera que la democratización y la buena gobernanza no son sólo fines en sí mismos, sino que además son de vital importancia para la reducción de la pobreza, el desarrollo sostenible, la paz y la estabilidad; considera que, como demuestra el proceso de integración interna de la Unión Europea, la democracia contribuye a la instauración no solo de los derechos políticos y civiles, sino también de los derechos económicos, culturales y sociales, incluida la solidaridad.

8. Destaca que la democracia no puede exportarse o imponerse desde el exterior y que una estrategia fructífera para la promoción de la democracia debe basarse en el diálogo e ir acompañada de importantes esfuerzos en pro del refuerzo de la sociedad civil y la sensibilización en cuanto a la democracia en los países en desarrollo; subraya el compromiso asumido ininterrumpidamente por la UE en relación con los principios de propiedad de las estrategias y los programas de desarrollo por parte de los países socios; señala, no obstante, que estos procesos pueden apoyarse mediante los diferentes instrumentos comunitarios, adaptados a la situación específica de cada país.

¿Y qué ocurre cuando nos encontramos con diversas formas de llevar a cabo la democracia? ¿Se cuenta con los elementos básicos que la definen? Para el Parlamento Europeo, en la Resolución citada,

«aunque los sistemas democráticos pueden variar en cuanto a su forma y configuración, como ocurre en el seno de la UE, la democracia es un valor universal y sus principios o elementos fundamentales están consagrados en numerosas declaraciones y convenciones internacionales». Esos principios o elementos fundamentales son: 1 . el respeto de los derechos humanos y las libertades fundamentales, como la libertad de asociación y de reunión pacífica, la libertad de expresión y la libertad de opinión; 2. el derecho a participar en la gestión de los asuntos públicos, directamente o por medio de representantes libremente elegidos, así como a votar y a ser elegido en elecciones verdaderamente periódicas y libres por sufragio universal e igualitario y mediante voto secreto que garantice la libre expresión de la voluntad del pueblo; 3 . un sistema pluralista de organizaciones y partidos políticos; 4. el respeto del Estado de Derecho; 5. la separación de poderes y la independencia del poder judicial; 6. la transparencia y la responsabilidad de la administración pública; 7. la existencia de medios de comunicación libres, independientes y pluralistas.» 
Para los críticos, como Nicolás Angulo Sánchez ${ }^{21}$, la gobernanza, término que procede el mundo empresarial, es en realidad «el conjunto de normas y procedimientos políticos y administrativos adecuados a la aplicación o implementación de los programas económicos propios de la «globalización o mundialización neoliberal» y caracterizados por la primacía del sector privado y de sus valores (competitividad, rentabilidad, productivismo y consumismo), así como por la subordinación a éstos de los sectores público y civil»; el término trata de legitimarse al adjetivarla como democrática o buena gobernanza. Angulo acusa a la Comisión Europea de seguidismo a Estados Unidos y las instituciones financieras internacionales, hecho que queda evidente en la Comunicación de la Comisión de 2003, en los capítulos dedicados al «Apoyo presupuestario (2.9), Comercio (2.10) y Sector empresarial (2.11). Así, por ejemplo, la Comisión reconoce que «la CE empezó a conceder apoyo presupuestario a los programas de reforma económica de los países ACP (África, Caribe y Pacífico) hará unos quince años, en el contexto de los programas de ajuste estructural acordados por estos países con las instituciones de Bretton Woods. Más recientemente, el apoyo presupuestario se ha ido extendiendo a otras regiones, aparte de los países ACP» (párrafo 43)».

Uno de los terrenos delicados para medir el alcance de las opciones europeas en gobernanza y desarrollo es el ámbito comercial. Aquí la UE proclama que es el socio comercial más abierto del mundo; conviene recordar que esa misma afirmación, con algún matiz, la pronuncian las principales potencias comerciales globales, mientras, especialmente en época de crisis, el proteccionismo, con distintos camuflajes, avanza considerablemente.

Queda por resolver la sempiterna reforma de la Política Agraria Común (PAC), que sigue siendo el elemento más contrario a la aplicación del principio de coherencia que proclama la Unión; los enormes intereses generados por el negocio de la alimentación parecen barreras infranqueables para lograr una PAC que permita a la UE ser un auténtico socio en el desarrollo.

Además, fruto de la combinación entre la defensa de intereses comerciales y la necesidad de aumentar la presencia en un mundo cada vez más competitivo, hay todo un despliegue que facilita que las empresas europeas cuenten con el apoyo de las instituciones en un marco de liberalización, lo que puede llegar a se incongruente con la defensa de las posiciones que la misma UE tiene en materia de desarrollo. Prueba de ese apoyo es la Comunicación de la Comisión Europea titulada «Una Europa global: competir en

21 ANGULO SÁNCHEZ, N., «Gobernanza y desarrollo», artículo publicado en la revista Pueblos, núm. 28, septiembre 2007, disponible en http://alainet.org/active/19982\&lang=es 
el mundo» ${ }^{22}$. La Comisión, al definir la contribución a la Estrategia de crecimiento y empleo de la UE, establece que «Esta agenda interna debe complementarse con una agenda externa para la creación de oportunidades en una economía globalizada, que englobe nuestras políticas comerciales y otras políticas externas. En los últimos años, nuestra prioridad externa en este ámbito ha consistido en tratar de lograr un acuerdo ambicioso, equilibrado y justo para liberalizar aún más el comercio internacional, abriendo con ello mercados en los que puedan competir las empresas europeas y proporcionando nuevas oportunidades de crecimiento y desarrollo». Es difícil, desde luego, trazar la línea roja que separa el apoyo a la internacionalización de las empresas europeas desde prácticas liberalizadoras, y la existencia de una política de desarrollo que tiene que basarse en la situación, la mayoría de las veces injusta, en la que están los países subdesarrollados, muchas veces expoliados por los negocios de las grandes corporaciones internacionales, muchas de ellas europeas.

\section{Conclusiones: un futuro incierto}

Aunque el proceso de integración europea ha vivido permanentemente en crisis - dando a este concepto el elemento positivo que también tiene-, el europesimismo campa de nuevo a sus anchas y la Unión Europea ya no se percibe como la solución, sino como el problema especialmente de los males económicos. En todo caso, se critica a la UE no por lo que hace, sino por lo que no hace o por su excesiva pasividad. Es cierto que a ese panorama contribuye la ausencia de un liderazgo europeo; al contrario, la defensa del interés nacional se prioriza por encima del interés común europeo.

Además de las opciones sobre cómo salir de la crisis, incluyendo los rescates a los socios en peores condiciones, la UE tiene varios frentes abiertos que definirán su próximo futuro. Son los casos, por ejemplo, de las ampliaciones (con el visto bueno al ingreso de Croacia y los dilemas en torno a Turquía) y, muy especialmente, de la negociación del marco financiero plurianual 2014-2020, ya que en ella se demostrará el grado de consenso entre las partes implicadas: la Comisión, los Estados miembros y el Parlamento Europeo.

No debemos olvidar que si por algo destaca ese proceso de integración es por su capacidad de regeneración y por encontrar opciones europeas para revitalizarse. Se suele mirar a lo que sucede a cada instante, olvidando que la

${ }^{22} \operatorname{COM}(2006) 567$ final, Bruselas, 4.10.2006. 
Unión ha conseguido avances en muchos campos a lo largo de su historia. Lo que hoy se echa de menos es a la Europa política, que supera con creces las tímidas respuestas intergubernamentales frente a ciertos problemas.

Los principios y valores europeos, además del método europeo de integración, han tenido un reconocimiento generalizado y han servido de referencia a otros mecanismos de integración regional, aunque hoy cotice a la baja por su incapacidad para gestionar de forma colectiva asuntos generales. Además, la deriva a estribor de buena parte de los Gobiernos de los Estados miembros, que tiene su correlato en las instituciones europeas, reorienta las políticas europeas hacia opciones conservadoras que ponen en cuestión el propio modelo europeo. Como ejemplo - más bien lo contrario - tenemos el caso del tratamiento europeo al hecho migratorio.

La Unión Europea, aunque hoy no lo parezca, ha sido pionera en la gestión compartida de asuntos de interés común, introduciendo métodos innovadores desde una política efectiva de multilateralismo. Esa naturaleza la convierte en la primera democracia transnacional del mundo. La crisis que sufre, no sólo económica, social y política, sino fundamentalmente de identidad, pone en riesgo lo conseguido pero, en línea con lo comentado anteriormente, tiene también el acervo y los recursos para ocupar el espacio que le corresponde para liderar la defensa de la democracia, la paz y la seguridad, los derechos humanos y el desarrollo. Si no lo hace la Unión Europea ¿quién lo va a hacer?

\section{Bibliografía}

AidWatch, Challenging Self-Interest. Getting EU aid fit for the fight against poverty, informe 2011 de la plataforma de ONGD europeas CONCORDE, disponible en http://aidwatch.concordeurope.org/static/files/assets/7bdf51c9/ CONCORD_2011.pdf.

BOOTH, S., HERBERT, S., EU external aid: who is it for?, Londres, Open Europe, abril 2011; en http://www.openeurope.org.uk/research/EUaid2011.pdf «El Servicio Europeo de Acción Exterior», Cuadernos Europeos de Deusto, núm. 44/2011.

EUROPEAN THINK-TANKS GROUP, «Nuevos desafíos, un nuevo comienzo: Próximos pasos en la cooperación al desarrollo europea», febrero 2010. Se puede consultar en la página de FRIDE: http://www.fride.org/publicacion/721/ los-proximos-pasos-en-la-cooperacion-europea-al-desarrollo.

EUROPEAN THINK-TANKS GROUP, «The EU's Multi-Annual Financial Framework Post-2013: Options for EU Development Cooperation», junio 2011. Disponible en la página del ODI (Overseas Development Institute, en el European Development Cooperation Strengthening Programme (EDCSP), http:// international-development.eu/. 
GRANELL, F., La coopération au développement de la Communauté Européenne, Institut d'Etudes Européennes de l'Université de Bruxelles (Collection Commentaire J. Megret), 2005.

HOEBINK, P. (ed.), European Development Cooperation - In Between the Local and the Global. Amsterdam, Amsterdam UP, 2010.

LESTRADE, E., «The Impact of the European Union's Development Aid Policies», International Trade Law Review, Sweet \& Maxwell, 2007.

SOTILLO, J. Á., Un lugar en el mundo. La política de desarrollo de la Unión Europea, Madrid, IUDC - Los Libros de la Catarata, 2006. 